\title{
Estructura de incentivos e instituciones en el pensamiento económico español del siglo XVII
}

\author{
Victoriano MARTÍN MARTÍN \\ Universidad Católica de Ávila \\ victoriano.martin44@gmail.com \\ Nieves SAN EMETERIO MARTÍN \\ Universidad Rey Juan Carlos \\ nieves.sanemeterio@urjc.es
}

Received: 05/08/2016

Accepted: 02/11/2016

\begin{abstract}
Resumen
Este papel recoge algunas de las consideraciones del pensamiento arbitrista sobre la estructura institucional de España en el siglo XVII. En concreto repasamos su reflexión respecto a los mayorazgos, vínculos, censos y juros. También revisamos sus críticas a la administración de justicia. Consideramos que sus argumentos, de corte absolutamente económicos, son muy similares a los utilizados por la Nueva Economía Institucional y el Análisis Económico del Derecho de la actualidad.
\end{abstract}

Palabras clave: arbitrismo, instituciones, análisis económico del Derecho

Clasificación JEL: B15, K0

\section{Incentive structure and institutions in the 17th century Spanish economic thought}

\begin{abstract}
This paper reviews some of the considerations about the institutional structure of Spain in the Arbitrism thought in the $17^{\text {th }}$ century. Specifically we review its reflection on primogeniture, entails, emphyteusis and juros. We also review their criticism of the administration of justice. We think their arguments have an absolute economic perspective and they are very similar to those used in the New Institutional Economics and Law and Economics today.
\end{abstract}

Keywords: arbitrism, institutions, law and economics

JEL Classification: B15, K0

\section{Introducción}

Existe un consenso general en la historia económica respecto de la divergencia que en el siglo XVII experimentaron países del norte de Europa como Holanda y Gran Bretaña y los del Sur como España. Las aportaciones de la Nueva Historia Económica en las últimas cuatro décadas han proporcionado argumentos significativos sobre las causas de este diferente devenir económico. Los trabajos ya clásicos de North $(1993,1994)$ y de North y Thomas (1991) pusieron de manifiesto que la estructura institucional de las naciones es determinante para entender el crecimiento o estancamiento, y así, desde entonces, el historiador y el economista se interesaron por ese entramado de normas que condicionan la estructura de incentivos de los individuos.

Esta nueva corriente de investigación en economía ha dado también sus frutos en otra disciplina: la historia del pensamiento económico. Hasta hace poco tiempo el historiador de pensamiento económico se dedicaba a estudiar la teoría económica ortodoxa, es decir, a estudiar qué dijeron los autores del pasado sobre lo que se consideraba economía. La determinación de los precios, el funcionamiento de los mercados, el papel del dinero, la inflación, eran los temas principales a tratar. Pero con la aparición de la Nueva Economía Institucional, la esfera de lo económico se ha ampliado. La estructura de los derechos de propiedad, el papel de los tribunales, las leyes, los costes de transacción dentro y fuera de las organizaciones, e incluso la organización del Estado son ahora aspectos que interesan al economista. Por ello se hace urgente revi- 
sar la historia del pensamiento tradicional para hacer una relectura de los autores del pasado. Se plantea un nuevo objetivo: descubrir si estos autores elaboraron explicaciones economicistas sobre la influencia que un conjunto determinado de derechos o prácticas jurídicas tiene sobre el desarrollo económico. ${ }^{1}$

El propósito de este artículo no es otro que revisar la obra de los arbitristas españoles del siglo XVII con el propósito de realizar un pequeño estudio de historia del pensamiento económico digamos "institucional". Creemos necesaria esta revisión por varios motivos. En primer lugar porque la perspectiva general que se tiene del arbitrismo es la de un cuerpo de ideas incoherente, sin atisbo alguno de lógica económica. ${ }^{2}$ Esta supuesta mala fama, cuyo origen probablemente esté en la interpretación que los ilustrados españoles confirieron a estos escritores del siglo XVII, puede no estar justificada si nos detenemos en analizar qué dijeron sobre el papel de las instituciones de su época. ${ }^{3}$ Este proceso de rehabilitación del pensamiento arbitrista no es caprichoso; importantes autores han reconocido que los arbitristas no erraron en sus recetas de política económica. ${ }^{4}$ Tal vez la alabanza mayor ha sido la de Earl J. Hamilton. En su estudio sobre las causas de la decadencia española del XVII señala:

En este grave apuro nacional los economistas acertaron -por una vez- en sus diagnósticos y prescripciones. Con visión profética los economistas españoles del siglo XVII (...) denunciaron la mayor parte de los males que llevaban a España a la ruina, tales como los mayorazgos, la mano muerta, la vagancia, la despoblación forestal, el exceso de eclesiásticos, el menosprecio del trabajo y las artes manuales, el reparto indiscriminado de limosnas, el caos monetario y la tributación excesiva. (...) La historia consigna pocos ejemplos bien de un tan acertado diagnóstico, bien de una tan terrible desatención por parte de los hombres de Estado. (Hamilton, 1984, p. 137)

Como veremos más adelante este descubrimiento de las causas de la decadencia española por parte de los arbitristas requería de un conocimiento preciso de la estructura institucional que había adoptado España y, lo que es más importante aquí, del conocimiento de los efectos económicos que acarreaba esta estructura. Si comparamos el razonamiento que había detrás de estos estudios sobre la decadencia de Castilla, veremos que poco se alejan del realizado por los autores de la Nueva Economía Institucional. Entonces como ahora hubo mentes preclaras que coligieron que las confiscaciones de la propiedad y los límites impuestos por parte de las prácticas legales impedían el pleno aprovechamiento de los recursos y, en definitiva, llevaban a España a la ruina. Este papel quiere dejar prueba de ello. En su recorrido abordaremos en primer lugar las reflexiones de estos autores en relación a la propiedad; aquí también veremos cómo los arbitristas denunciaron algunos instrumentos financieros que provocaban efectos perversos en la estructura de incentivos, tal es el caso de los censos y los juros; en segundo lugar veremos brevemente sus críticas a la administración de justicia, críticas que se asemejan a las expuestas hoy en día por los autores del análisis económico del Derecho. Por último haremos una breve comparación del alcance de estas ideas con el del mercantilismo inglés coetáneo.

Somos conscientes de que el análisis económico de las leyes abarca muchas más cuestiones; por ejemplo, la discusión de la fiscalidad está claramente dentro de este campo habida cuenta de

\footnotetext{
${ }^{1}$ Un trabajo pionero en este campo es el de Ekelund y Tollison (1981).

${ }^{2}$ Como señalan Marjorie Grice-Hutchison (1982, pp. 189-190 y Gordon (1982, pp. IX-XIV) existen dos calificativos para los autores que diseñaron proyectos para restaurar la prosperidad en España del siglo XVII: los arbitristas y los economistas políticos. Desde la acuñación de la palabra "arbitrista" ésta tuvo connotaciones negativas y así en el pensamiento económico español se hablaba de unos u otros en función de la opinión que merecieran sus ideas. En general para aquellos que se consideraban de mayor valía se les denominaban economistas políticos. Aquí nos referiremos indistintamente a ellos como economistas políticas y como arbitristas pero desechamos la connotación negativa que pudiera tener el término.

${ }^{3}$ Sobre la herencia del arbitrismo en los autores del siglo XVIII, ver Perdices, (1996, cap.6). También sobre este tema ver Gordon (1982, pp. IX-XX).

${ }^{4}$ Recientemente Miguel González Moreno (2015) trata de poner luz sobre el origen del componente peyorativo del término arbitrista en la literatura del Siglo de Oro y aclara la extensión del término a mercantilistas y economistas políticos.
} 
que son las normas impositivas las que determinan la presión fiscal y fueron temas que los autores del XVII trataron con profusión. Esta discusión, como la relativa a la devaluación del vellón o a la tasa de grano, está completamente dentro del enfoque institucional que queremos hacer. Sin embargo pensamos que este estudio ha formado parte del enfoque tradicional del pensamiento económico español. ${ }^{5}$ Por ello nos detendremos en otras consideraciones que, aunque pueden ser menores, caen de lleno en el enfoque institucional.

\section{Los derechos de propiedad en los arbitristas}

Las diferencias existentes entre la obra de los teólogos españoles del XVI y XVII y los economistas políticos son bien conocidas. Por lo general la Escuela de Salamanca y los teólogos jesuitas como Molina o Suárez han dado frutos de incuestionable valor dentro y fuera de la ciencia económica. En comparación, los arbitristas contemporáneos quedaron en una pobre posición. Por ejemplo, y sólo sobre cuestiones puramente económicas, mientras que Azpilcueta enunciaba por primera vez la teoría cuantitativa del dinero en su Comentario resolutorio de cambios en 1556, el arbitrista Sancho de Moncada, aun conociendo esta teoría, comete flagrantes contradicciones al afirmar en alguna ocasión que "el subir el precio de las cosas no resulta en España del valor de las monedas, alto o bajo" (1974, p. 148). ${ }^{6}$ Aun siendo cierto que existen objeciones mayúsculas en el pensamiento arbitrista, hemos de reconocer que éstos no aspiraban a la construcción de teorías, antes bien, a crear política económica ad hoc. Como resumió GriceHutchinson, existen diferencias sustanciales entre los escolásticos y arbitristas en la metodología y objetivos; sin embargo, no impide que convengamos con ella que "los fundadores de las ciencia económica en España se contaran en los dos grupos" (1982, p. 163).

El debate sobre la propiedad entre teólogos y economistas políticos es otro ejemplo del diferente objetivo de estos dos grupos de autores. La Escuela de Salamanca y otros teólogos españoles elaboraron una discusión completa sobre la definición, justificación y límites de la propiedad privada. Su discusión era meramente teórica y su especulación tenía escasa conexión con el tipo de prácticas llevadas a cabo en la España de su época. ${ }^{7}$ Nada parecido existe en los arbitristas del XVII; en sus memoriales no aparece un estudio preciso de la propiedad, tan sólo discuten sobre cómo su reparto o sus limitaciones legales afectan a los incentivos productivos. ${ }^{8}$ Dan por sentado que la propiedad privada existe y se limitan a criticar determinadas prácticas como los mayorazgos y las vinculaciones. Más de un siglo después Adam Smith iba hacer lo mismo en sus "Lecciones de Jurisprudencia" (1995, 102-103) y en La Riqueza de las Naciones (1988, 433-439).

Veamos dónde y cómo critican los arbitristas precisamente estas dos prácticas jurídicas. Martín González de Cellorigo (1991 [1600], III, p. 169-172), Pedro de Valencia, (1994 [1607], pp. 150-158), Mateo López Bravo (1977 [1616], pp. 268-272 y 287-288), Pedro Fernández de Navarrete (1982 [1626], Discurso XI, pp. 95-97 y 99-106), y Miguel Caxa de Leruela (1975 [1627], I, cap. XXI, pp. 54-59) son algunos de los arbitristas que vieron el perjuicio que conllevaba la concentración de la herencia en el primogénito y la imposibilidad de fragmentación y venta de la heredad que implicaban los vínculos. El discurso es muy similar en todos ellos y se puede resumir de la forma siguiente: la acumulación de la propiedad de la tierra en unas solas manos impide que se reparta entre la población que realiza actividades realmente productivas mientras que el heredero único rápidamente se convierte en rentista y el ocio y la vagancia hacen acto de presencia. Por si fuera poco, esta desigual distribución de la propiedad extiende la

\footnotetext{
${ }^{5}$ Por ejemplo el estudio ya clásico sobre los economistas políticos de Marjorie Grice-Hutchinson (1982) incorpora el análisis de las finanzas públicas y de la moneda.

${ }^{6}$ Sobre el cuantitativismo de Moncada ver Fernández Delgado (2006, pp. 171-175).

${ }^{7}$ Sobre este tema ver San Emeterio (2005, cap. I).

${ }^{8}$ Vázquez de Menchaca, un jurisconsulto del XVI, es un caso particular sobre este tema ya que recupera la tradición escolástica de la propiedad para justificar problemas concretos relativos a la propiedad, por ejemplo si es lícito o no el apresamiento de barcos extranjeros en aguas internacionales (San Emeterio, 2005, pp. 90-117).
} 
pobreza y la despoblación a todos los campos de la nación. Entre todos estos textos merece la pena resaltar las críticas de López Bravo a las vinculaciones:

No hay verdadera opulencia sin posesiones, ni confianza ni crédito; las fincas son el fundamento de las riquezas y toda industria y el esfuerzo y el trabajo de los ciudadanos va encaminado a reunir dinero para poder comprar estos verdaderos bienes, las fincas. Si prohibimos el comercio de propiedades a muchos se les cierra el camino para convertirse en propietarios. Los vínculos de las propiedades llenan, pues, el Estado de miserables y desesperados. No debe, pues aplicarse esta prohibición legal al donante o al que vende por partes. (López Bravo, 1977, pp. 288-289)

Una cita de sorprendente parecido la podemos encontrar en Adam Smith cuando valora el derecho a establecer vínculo en las tierras:

Este derecho no sólo es absurdo en el más alto grado, sino que es extremadamente perjudicial para la comunidad, pues excluye por completo las tierras del comercio. El interés del estado requiere que las tierras permanezcan en el comercio como cualquier otro bien. Esto excluye enteramente el poder de hacer vínculos. (Smith, 1995, p. 102)

Smith utiliza argumentos idénticos a los arbitristas cuando aborda las consecuencias económicas de estas prácticas hereditarias. La primogenitura y las vinculaciones -señala- son normas que desincentivan las tareas agrícolas; "un gran propietario pocas veces mejora sus tierras" y normalmente se preocupa más "por el lucimiento que satisface sus caprichos que por los beneficios que no necesita" (Smith, 1988, p. 438). Por el contrario, "si esta propiedad se dividiese en varias posesiones pequeñas, cada una con un amo distinto, estaría pronto muy bien cultivada" (Smith, 1995, pp. 102-103).

En consecuencia la política correcta tanto para los arbitristas, como para Smith, será bien "quitar el uso de los vínculos y mayorazgos que prohíben la enajenación, en cuanto a la prohibición del traspaso" (González de Cellorigo, 1991, p. 171), bien limitar su fundación a las grandes propiedades, pues "habiendo de ser los vínculos tan cuantiosos, no serían tantos los que para fundarlos desamparasen la labranza, la crianza, las artes y los oficios" (Fernández Navarrete, 1982, p.96).

Muy unida a esta discusión sobre el reparto de propiedades aparece la crítica a los censos y a los juros. Estos activos financieros, privados los primeros y públicos los segundos, posibilitaba que los grandes propietarios abandonaran las labores productivas a cambio de obtener unas rentas fijas prácticamente a perpetuidad. Fernández Navarrete incorpora su crítica al hablar de los mayorazgos y vínculos:

A este daño han dado motivo los juros; porque como los que con su trabajo han adquirido alguna hacienda, hallan que por medio de ellos pueden tener rédito descansado, desamparando las artes y oficios, la labranza y crianza en que ganan con sudor la comida: con lo que viene a menguar el comercio, y con él los derechos reales: porque el mercader deja el trato, el oficial su tienda, el hidalgo que labraba sus heredades, las vende y las subroga en juros, el tratante deja las navegaciones, cesando con esto la venta de los frutos naturales e industriales en que se estaba librada la riqueza de las ciudades, con lo cual faltándose en qué ocuparse los vecinos se despueblan los lugares a que se tiene menos amor, cuando no se tiene en ellos hacienda raíz; y con esto, siendo España de las más fértiles provincias del mundo (...) está infamada de estéril. (Fernández Navarrete, 1982, pp. 95-96)

Los juros, al igual que los mayorazgos y vínculos, alteran la estructura de incentivos de tal modo que desaparece todo estímulo hacia las labores productivas y constituye uno de los principales males de España para el pensamiento arbitrista. "Censos, juros, vínculos y mayorazgos (reclinatorio de esta holgazanería)" -apunta Caxa de Leruela- son mucho "más perjudiciales que la misma Ociosidad: porque los hace causa de ello, no efectos" (1975, p. 55). Moncada a este respecto señala que es "discurso del perezoso" tener renta en paz que mucha hacienda en cuidados (1974, p. 208). Para Lope de Deza el censo es "una invención de un rico holgazán y codicioso y de un pobre miserable y necesitado" y añade que cuánto mejor sería que las haciendas se comprasen y vendiesen libremente en vez de tomar los censos forzosos. Así, "el pobre 
trabajará para sí, el rico se ocupará virtuosamente sin atender al sudor y miseria de los que cada día están aprisionando y afligiendo, y no estuviera su vida tan ocasionada a la ociosidad y vicios que de ella se siguen" (de Deza, 1991, p. 59). Para López Bravo, el censo es aún peor que la usura, "porque aficionando cada día más gente y de manera más grave, disminuye los negocios y aumenta al ocio". No existe cosa peor que la compra de una renta anual -y añade-, "la consecuencia es la haraganería general, el lujo, la ruina y el despoblamiento de los pueblo". La solución está en "prohibir para el futuro compras de réditos anuales e ir disolviendo poco a poco las pasadas y devolver su libertad originaria a las posesiones e ingresos regios". Una vez suprimidas las servidumbres de las rentas anuales, su dueño "no tendrá más remedio que emplearla [su fortuna] en el cuidado del ganado, de los campos o de las mercancías" (López Bravo, 1977, pp. 272-276). González de Cellorigo, por su parte, pone el énfasis en el mal que produce al reino que se eliminen del mercado las tierras con este tipo de cargas, "huyendo todos de comprar bienes hipotecados y acensuados, se suelen las tierras labradas antes perder que haber quien quiera entrar en ellas y darles las labores necesarias a la buena esperanza del fruto que prometen". Por ello, aunque pueda ser complicado abolir prácticas antiguas, Cellorigo advierte que no mudar esta costumbre o ley es cosa peligrosa y sería como "quitar la medicina al enfermo" (1991, pp. 173-175).

En resumen, no hay duda de que los arbitristas descubrieron los efectos perversos de mayorazgos, vinculaciones, censos y juros. Para el propósito de este papel, el argumento de mayor interés esgrimido guarda relación con los límites a los derechos de propiedad que conllevaban estas prácticas legales. La prohibición de enajenación en el caso de mayorazgos y vínculos, y la salida del mercado de las tierras sobre las que pesaban juros o censos, limitaban la amplitud del mercado y, por lo tanto, impedía que las tierras fueran a manos de quien quisiera aprovecharlas más eficientemente. Un razonamiento similar al que pudiera hacer un economista actual que se dedique al análisis económico del Derecho. Para estos autores, como para los arbitristas, "la creación de derechos exclusivos es una condición necesaria, pero no suficiente, para el uso eficiente de los recursos: los derechos deben ser transferibles. (...) La eficiencia requiere un mecanismo que pueda inducir al agricultor a transferir la propiedad a alguien que pueda trabajarla más productivamente. Un derecho de propiedad transferible es tal mecanismo".

\section{Los costes de la justicia}

Otro de los aspectos que queremos destacar del pensamiento arbitrista es el relativo a los problemas que observaron en la administración de justicia. Como en el caso anterior, creemos que sus razonamientos tienen muchos paralelismos con los estudios actuales sobre los costes económicos asociados a la ejecución de la ley. ${ }^{10}$

La crítica de los arbitristas es doble aunque una y otra están relacionadas: por una parte consideran que hay excesivas leyes y, por otro, que los pleitos tardan mucho en resolverse. Fernández Navarrete es uno de los autores que vincula la crítica al sistema jurídico en general con la dilación en la administración de justicia:

es cierto que con estas leyes del derecho común [se refiere a las Partidas], y con las varias interpretaciones de tantos autores como cada día salen a comentarlas, y con tantas opiniones encontradas, se embrolla y entrampa la justicia de los que la tienen, acabándose la vida de los litigantes, y consumiendo sus haciendas en sutilezas de letrados, con que jamás se pone fin a los pleitos, hallándose los jueces embarazados con tantas informaciones cargadas de alegaciones de infinitos autores, a que no se debe tener atención. (Fernández Navarrete, 1982, p. 334)

\footnotetext{
${ }^{9}$ Ver en este sentido el capítulo III del libro clásico de esta disciplina de donde está extraída la cita, Posner, (1998, p. 39).

${ }^{10}$ Ver en este sentido Santos Pastor (1989, cap. IX). Pastor clasifica estos costes del sistema jurídico en varias categorías: las tasa judiciales; los honorarios profesionales de abogados, procuradores, peritos, expertos, notarios, registradores, etc.; los gastos de transporte y otros; una serie de "costes de oportunidad", como imposibilidad para trabajar debido al tiempo que ha de dedicar a resolver los pleitos; y la dilación (p. 242). Para un estudios completo sobre el análisis económico de la administración de justicia ver Santos Pastor (1993).
} 
Desde el punto de vista económico lo más interesante es el alto coste de oportunidad que acarrea la dilación de los pleitos especialmente entre los labradores "que pierden su trabajo personal, en que tiene librado su sustento" (Fernández Navarrete, 1982, p. 335). Su propuesta será eliminar del sistema jurídico aquellas leyes que han sido abrogadas o han caído en el desuso. Idéntica prescripción para el mismo problema es apuntada por López Bravo,

Para reducir al silencio todos estos males y para que toda esta gente [procuradores y abogados] se encamine al valor de las armas o a la sobriedad de los campos, modera la cantidad y sobriedad de los pleitos, limitando el número y la ambigüedad de las leyes así como los amplios plazos judiciales y excluyendo por completo los volúmenes de los comentadores. (López Bravo, 1977, p. 279)

Moncada insiste también en la necesidad de reducir el cuerpo legal. Es preciso -señala"quitar o mudar las leyes que el tiempo y nuevas circunstancias han hecho inútiles, o dañosas a España". Ahora bien, las que queden habrán de ser inquebrantables (Moncada, 1974, pp. 202203).

Jerónimo de Cevallos, en su Arte Real, dedica abundantes páginas a estudiar los perjuicios causados por la abundancia de leyes. Igual que Navarrete, Cevallos cree que el exceso de leyes produce una infinidad de opiniones que hacen que se multipliquen los pleitos. Y así dice que

Siendo el fin de las leyes, para el quieto y pacífico estado de la República, la vemos más inquieta con las guerras civiles que causan los pleitos, como se ve en todos los tribunales, comiendo y triunfando a costa de los pleitos tanto número de gentes, como son jueces, abogados, escribanos, procuradores, solicitadores, escribientes, y otros muchos ministros que dependen de ellos, que tienen más seguras sus rentas (...) que los que tienen casa, y viñas, censos, y juros, porque todos estos pasan necesidad porque unas veces la heredad no lleva fruto, otras se hiela, y otras veces no caben los juros, ni se pagan los censos: pero los pleitos son la hierba que llaman 'siempreviva', que nunca falta ni se seca. (Cevallos, 2003, p. 164) ${ }^{11}$

La solución, como en los autores anteriores, es la reducción del número de leyes. Pero Cevallos, cuando estudia cómo ha de aplicarse esta labor de depuración legal, observa que las Repúblicas que se gobiernan sin leyes, únicamente por las costumbres "son más fáciles de gobernar y más dificultosas de revocar" (Cevallos, 2003, 165). Un argumento seguramente menor pero que hoy recobra importancia porque ciertas investigaciones consideran que el sistema jurídico de Common Law, de origen consuetudinario, provee al sistema económico de una estructura legal más eficiente que los sistemas jurídicos basados en códigos civiles. ${ }^{12}$

Merece la pena destacar el estudio de Lope de Deza sobre el tema que nos ocupa. Más que ningún otro considera un grave problema que los agricultores pierdan su tiempo en litigios; su coste de oportunidad es tan dañino para la economía que idea una reforma completa de la justicia ordinaria para que éstos eviten perder su tiempo fuera de las labores propiamente agrícolas. Propone, en primer lugar, que sean los alcaldes de los lugares de residencia de los labradores quienes tengan la jurisdicción sobre estos pleitos; así se evitaría los costes y tiempo del desplazamiento. También piensa que se abreviarían los procesos si las partes de viva voz se reuniesen en un mismo lugar y a un mismo tiempo, sin necesidad de que se escribiesen los pleitos. Esta especie de juicios rápidos se deberían producir en los días "lluviosos y desocupados de las labores, (...) y se podría mirar si esto conviniese en algunos días festivos en la tarde que ellos suelen ocupar en juegos o en otras haciendas" (Lope Deza, 1991, pp. 187-188).

\footnotetext{
${ }^{11}$ Por ser una edición facsímile se ha hecho la trascripción al castellano moderno.

${ }^{12}$ Según Posner, la Common Law posee una mayor capacidad de adaptación al medio (2000, p. 228). En este mismo sentido cabe señalar que las recientes investigaciones sobre el plazo medio de duración de litigios corroboran la superioridad del sistema de Common Law respecto de otros sistemas legales (MoraSanguinetti, 2016, p. 36).
} 
En definitiva, podemos concluir que los arbitristas españoles hicieron un completo estudio de la administración de justicia de su tiempo. De todo ello nos interesa aquí el componente económico de sus argumentos, por ejemplo, cómo observaron que los largos litigios conllevaban costes directos -los derivados de las retribuciones a jueces, procuradores, escribanos, etc.- y los indirectos medidos en términos de coste de oportunidad de quienes se dedican a otras labores productivas. Además idearon una reforma para reducir estos costes y simplificar el sistema jurídico, una reforma necesaria para el restablecimiento de la salud de la nación. Si comparamos todos estos estudios con el análisis económico de las instituciones judiciales que se lleva a cabo en la actualidad las semejanzas del enfoque están claras; ambos estudian la eficiencia de la organización, esto es, si existe o no despilfarro de recursos; y para ambos la estructura de incentivos que crean estas instituciones son los aspectos centrales en sus discursos. Las preguntas que se plantearon los arbitristas del siglo XVII son básicamente las mismas que quiere resolver el análisis económico en la actualidad: “¿por qué pleitea la gente? ¿Cuánto cuesta a la sociedad que la gente pleitee? ¿Qué papel juegan los abogados en la potenciación o reducción de la litigiosidad? ¿Cómo afectarían los cambios en los costes de pleitear, en la tardanza o en otras variables a la consulta de los potenciales litigantes? ¿Existe en verdad un 'boom' de litigación? ¿Cuánto se tarda en obtener una sentencia penal, o contenciosa administrativa?" (Pastor, 1993, p. 21). Como hemos visto, los arbitristas contestaron a todos estos interrogantes.

\section{El análisis de las instituciones en Josiah Child}

Antes de terminar salgamos del continente por un momento y veamos cuál era el análisis institucional del gran mercantilista inglés Sir Josiah Child. Veremos si este autor compartía con los autores españoles el análisis institucional de las naciones de su época. En su obra Breves Observaciones relativas al comercio y al valor del dinero [1668] describe la estructura institucional de la nación rival de Inglaterra, Holanda, para descubrir los motivos de su prosperidad. Entre los factores que destaca de los holandeses está:

La ley Gavel-kind en virtud de la cual después de la muerte de sus padres, todos los hijos tienen derecho a compartir equitativamente la herencia, y de esta manera no se les abandona en su juventud a que se enfrenten con el mundo con la insignificante ayuda de una suma de dinero, como sucede con la mayoría de los hijos más jóvenes de nuestros caballeros en Inglaterra, quienes están destinados a ser aprendices de comerciantes (...).

El estímulo e inmunidades que ellos brindan a los inventores de nuevas manufacturas, a los descubridores de nuevos misterios del comercio (...). A cambio de ello los autores nunca se quedan sin la correspondiente recompensa que se les otorga con fondos públicos. (...)

$\mathrm{Su}$ ley mercantil, según la cual todas las controversias entre mercaderes y comerciantes se dirimen en el lapso de tres o cuatro días, y con un coste de menos de la cuadragésima parte (y debo decir que en algunos casos menos de la centésima parte) de los que pagarían entre nosotros". (Child, 1999, pp. 233-236)

Como en el arbitrismo español, Child incorpora el análisis institucional en su discurso. Estos tres puntos que hemos seleccionado nos dan muestra de que las leyes de la herencia, los derechos sobre la propiedad intelectual y la eficiencia en las normas para la resolución de conflictos estaban entre los factores que podían hacer que un país tomara una senda de crecimiento económico. Sin embargo, creemos advertir diferencias entre los arbitristas y Child. Los primeros consideraron que la estructura institucional de España era una causa directa del declive aunque, claro está, podía haber otras: la decadencia de la Mesta para Caxa de Leruela o la llegada de las manufacturas extranjeras para Martínez Mata, por ejemplo. Pero sólo existe una explicación para Child: la rebaja del tipo de interés. El discurso de Child está elaborado de tal forma que una vez enumera los posibles motivos por los que Holanda es la primera potencia mundial -entre los que incluye los citados arriba- opta por uno de ellos despreciando al resto. Podemos decir, por tanto, que el razonamiento mono-causal de Child desperdició su rica intuición sobre los efectos económicos del sistema legal. 


\section{Conclusiones}

A lo largo de la historia ha habido muchos autores que han reflexionado sobre las causas del retraso económico de España y el motivo por el que no se supo aprovechar las oportunidades que nos brindó la providencia para consolidar el crecimiento de este país. Algunos han creído que forma parte de la cultura española echarnos a holgar en vez de dedicarnos primero a pensar y segundo a trabajar. La ausencia de espíritu de empresa y la aversión al trabajo manual son dos factores esgrimidos tradicionalmente para explicar la decadencia española. Nosotros no lo creemos. La metodología de la ciencia económica debería rechazar tales explicaciones porque trabajamos bajo el supuesto de que todo ser humano, independientemente de etnias y culturas, es en nuestros postulados un mero homo ceconomicus y por tanto responde básicamente de la misma forma ante idénticos incentivos. La revisión del arbitrismo de las páginas anteriores nos da muestra de que los españoles del siglo XVII no eran más o menos perezosos o trabajadores porque lo llevaran impreso en sus genes, lo que sucedía era que respondían racionalmente ante el sistema de incentivos que había en esos momentos. Estos autores -como hacen actualmente quienes se dedican al análisis económico de las instituciones- fueron plenamente conscientes de que las limitaciones en los derechos de propiedad de la tierra que conllevaban mayorazgos, vínculos, censos o juros, eliminaba del mercado a las tierras e impedía su explotación más eficiente obstaculizando el acceso de los potenciales compradores. También consideraron los enormes costes directos y de oportunidad de una administración de justicia saturada de leyes que multiplicaba los pleitos y sus dilaciones. Todos estos factores desviaban a los trabajadores de tareas productivas.

Por último hemos de insistir en la parcialidad de este trabajo. Hemos dejado demasiadas cosas fuera que forman parte del comentario de los arbitristas a la estructura institucional. El más interesante -y también el más estudiado- es el relativo ya no a la limitación de los derechos de propiedad sino a las confiscaciones que llevaron los Austrias, lo que fue mucho más grave. Las devaluaciones de la moneda de vellón -como dijo Juan de Mariana- supusieron una confiscación de lo que pertenece por derecho al pueblo y ocasionaron enormes perjuicios. También hemos omitido toda reflexión sobre al sistema impositivo que, tanto entonces como ahora, es fundamental para que los individuos calculen su deseo de trabajar. Si contemplamos conjuntamente la estructura institucional del siglo XVII: la regresividad impositiva, las prácticas devaluatorias, el entresijo legal, las leyes de la herencia y los instrumentos financieros, podemos intuir que el comportamiento de los españoles era posiblemente el más racional. Pero lo más sobresaliente del asunto no es que podamos exculpar a nuestros ancestros por lo hoy sabemos; lo realmente relevante es que sus coetáneos fueron entonces conscientes de todo ello.

\section{Bibliografía}

Caxa de Leruela, Miguel. 1975 [1627]. Restauración de la Abundancia de España. Madrid, Instituto de Estudios Fiscales.

Ceballos, Jerónimo de. 2003 [1623]. Arte Real para el buen gobierno de los Reyes, y Príncipes $y$ de sus vasallos. Madrid, Centro de Estudios Políticos y Constitucionales.

Child, Josiah. 1999 [1668]. Breves observaciones relativas al comercio y al interés del dinero, en John Locke. Escritos Monetarios. Madrid, Pirámide.

Deza, Lope. 1991 [1618]. Gobierno político de agricultura. Madrid, Instituto de Estudios Fiscales.

Ekelund, Robert B. y Tollison, Robert D. 1981. Mercantilism as rent-seeking society: Economic regulation in historical perspective. Texas, Texas University Press.

Fernández Delgado, Rogelio. 2006. Liberalismo y estatismo en el siglo de oro español. Madrid, Unión Editorial.

Fernández Navarrete, Pedro. 1982 [1626]. Conservación de Monarquías y Discursos Políticos. Madrid, Instituto de Estudios Fiscales.

González de Cellorigo, Martín. 1991 [1600]. Memorial de la política necesaria y útil restauración a la república de España. Madrid, Instituto de Estudios Fiscales.

González Moreno, Miguel. 2015. Del arbitrismo al mercantilismo. eXtoikos, 16, 58-60. 
Gordon, Michael D. 1982. Moralidad y Política en la España del siglo XVII. Estudio Preliminar a Fernández Navarrete, Martín, Conservación de Monarquías y Discursos Políticos. Madrid, Instituto de Estudios Fiscales.

Grice-Hutchinson, Marjorie. 1982. El pensamiento económico en España, 1177-1740. Barcelona, Crítica.

Hamilton, Earl J. 1984. La decadencia española en el siglo XVII. En El Florecimiento del capitalismo. Madrid, Alianza Editorial.

López Bravo, Mateo. 1977 [1616]. Del rey y de la razón de gobernar, en López Bravo, Mateo, Un socialista español del Siglo XVII, edición de Henry Mechoulan. Madrid, Editora Nacional.

Moncada, Sancho. 1974 [1619]. Restauración política de España. Madrid, Instituto de Estudios Fiscales.

Mora-Sanguinetti, Juan S. 2016. Evidencia reciente sobre los efectos económicos del funcionamiento de la Justicia, Boletín Económico, Banco de España, enero, 33-41.

North, Douglass C. y Thomas, Robert P. 1991 [1973]. El nacimiento del mundo occidental. Una nueva historia económica (900-1700). Madrid, Siglo XXI.

- 1993 [1990]. Instituciones, cambio institucional y desempeño económico. México, Fondo de Cultura Económica.

- [1981] 1994. Estructura y cambio en la Historia Económica. Madrid, Alianza.

Pastor, Santos. 1989. Sistema jurídico y economía. Madrid, Tecnos.

— 1993. ¡Ah de la Justicia! Política Judicial y Economía. Madrid, Civitas.

Perdices, Luis. 1996. La economía política de la decadencia de Castilla en el Siglo XVII. Madrid, Síntesis.

Posner, Richard A. 1998. Análisis Económico del derecho. México, Fondo de Cultura Económica.

- 2000. El movimiento del Análisis Económico del Derecho. En Roemer, Andrés, (comp.), Derecho y Economía: una revisión de la literatura. México, Fondo de Cultura Económica, 221-241

San Emeterio, Nieves. 2005. Sobre la propiedad. El concepto de propiedad en la Edad Moderna. Madrid, Síntesis.

Smith, Adam. 1988 [1776]. Investigación sobre la Naturaleza y Causas de la Riqueza de las Naciones. Barcelona, Oikos-Tau.

- 1995 [1978]. Lecciones sobre Jurisprudencia, (Curso 1762-63). Granada, Comares.

Valencia, Pedro de. [1607] 1994. Discurso sobre el acrecentamiento de la labor de la tierra. En Obras Completas, IV/1. Salamanca, Universidad de León. 